\title{
Smoking Behavior Among 84315 Open-University Students in Thailand
}

Cha-aim Pachanee, BAppSc, MIH, Lynette Lim, PhD, Christopher Bain, MBBS, Suwit Wibulpolprasert, MD, Sam-ang Seubsman, PhD, and Adrian Sleigh, MD

\begin{abstract}
The aim of this study was to estimate the prevalence of smoking among students in an open university in Thailand and to describe smoking patterns in relation to the personal and social characteristics of the sample. A self-administered questionnaire survey was conducted in 2005 with 87134 open-university students in Thailand; the respondents aged 15 to 60 years $(N=84315)$ are the participants in this study. We found a substantial difference in smoking prevalence by sex, with a much higher proportion of smoking male $(20.9 \%)$ than female (1.0\%) students in all sociodemographic categories. Smoking decreased among men with a higher level of education or income; in contrast, among women, higher incomes were associated with more smoking. Most of the smokers started smoking in high school. The findings provide evidence that future policy making should aim to reduce smoking among the younger population in Thailand, and in particular, they point to the need to preserve low smoking rates among women.
\end{abstract}

Keywords: smoking; Thailand; trends; university students

\section{Introduction}

In Thailand, the proportion of smokers in the population has decreased in the past 3 decades from $54.7 \%$ in 1976 to $38.8 \%$ in 2006 in men and from $6.1 \%$ to $2.6 \%$ in women, although the intensity of smoking has increased in the same period. Thai smokers consumed an average of 87.6 packs of cigarettes each in 2005 compared with 71 packs per person per year in 2001-2002., ${ }^{1,2}$

Tobacco ranked as the third highest health risk, after unsafe sex and alcohol, in Thailand, in 2004, and contributed to 5.8\% (570 000 DALYs $\left.^{*}\right)$ of all DALYs lost. ${ }^{3}$ Smoking does not only pose health risks but also has direct and indirect economic impacts. Apart from income loss or increased expenses for treatment of smoking-related illnesses, the expense of

From the National Centre for Epidemiology and Population Health, The Australian National University, Australia (CP, LL, AS); the School of Population Health, The University of Queensland, Australia (CB); the Ministry of Public Health, Thailand (SW); Sukhothai Thammathirat Open University, Thailand (SS).

Address correspondence to: Cha-aim Pachanee, National Centre for Epidemiology and Population Health, The Australian National University, Building 62, Mills Road, Canberra ACT 0200, Australia; e-mail: chaaim.pachanee@anu.edu.au.

${ }^{*}$ DALY $=$ Disability adjusted life year. It is a time-based measure that combines years of life lost because of premature mortality and years of life lost because of time lived in states of less than full health. 
cigarettes can be considered as a household burden because, for example, for the population in Bangkok, $15.7 \%$ of monthly personal income was spent on cigarettes in $2003 .{ }^{4}$

Smoking remains widely prevalent among the younger population of 15 - to 24-year-olds in Thailand despite some recent improvements in the past 5 years, when the proportion of men who smoked at these ages decreased from $32.1 \%$ in 2003 to $29.0 \%$ and $26.4 \%$ in 2004 and 2006, respectively. These proportions are about half the levels noted in male adults aged 25 to 59 years, for whom the proportions were $49.6 \%$ and $48.3 \%$ in 2004 and $2006 .{ }^{1}$

Prevention of smoking or inducing smoking cessation at younger ages is desirable as it can reduce the health impact to a greater extent than smoking cessation at an older age. There has been no widely conducted study of smoking behavior among the young, specifically among university students in Thailand, and furthermore, available data cover only small samples in specific settings and are not contemporary. ${ }^{5}$ This article describes the results of a large-scale study of distance learning open-university students in Thailand who are from various backgrounds and geographic locations around the country. These findings are intended as a source of information for better-informed and targeted policy making and health education program development.

\section{Methods}

As part of the Thai Health Risk Transition Project, ${ }^{6}$ in 2005, a self-administered questionnaire was mailed to all 200000 students enrolled at Sukhothai Thammathirat Open University (STOU) in Thailand. These students range in age from 15 to 87 years, with most belonging to the 20 to 35 age group. The STOU is 1 of 2 open universities in Thailand and is open to anyone who has completed junior high school and has substantial work experience or those who have completed senior high school or equivalent diploma. Students study externally. In 2000, about $9.0 \%$ of the Thai population aged 6 years and older had received tertiary-level education. ${ }^{7}$ These 200000 students accounted for $4.1 \%$ of the population with tertiary education.

Responses were received from $87134(44 \%)$ students in all regions in the country with ages ranging from 15 to 87 years. Among these, 84315 of them were between 15 and 60 years old-the age limits of the analyses reported here. They reported a valid smoking status and were included in this analysis.

The survey covered wide-ranging information in 7 domains: (1) sociodemographic status, ethnicity, and the domestic environment in the present and past; (2) occupation, income, and work stresses; (3) self-reported current height (in centimeters) and weight (in kilograms), size at birth (reported to government registers by relatives), whether breast-fed, health history, and insurance and health services use; (4) social networks and trust, religion, spiritual health, and sense of well-being and satisfaction; (5) food sources, preferences and intake, and exercise and physical activity; (6) tobacco and alcohol use, use of transport, and transport injury risks; and (7) respondent's family health background. This survey has been described in more detail by Sleigh et al. ${ }^{6}$

Smoking status was derived from 5 questions. The first question was, "Have you ever smoked?" Those who reported they had were then asked the age at which they started ("At what age did you start smoking?"), whether they were still smoking ("Are you still smoking?"), age at which they stopped ("If you have quit smoking, at what age did you stop?"), and the number of cigarettes they smoked each day ("How many cigarettes do you smoke per day now, or did you smoke per day?”). This article presents results from descriptive 
analyses of smoking status in relation to sociodemographic-economic factors, including age, sex, education, income, geographic region, marital status, and home location. Smoking status was classified into 3 categories: current smoker, former smoker, and never smoker. The respondents who reported having smoked currently were classified as current smokers, those who reported having smoked and stopped were classified as former smokers, and those who reported that they never smoked were classified as never smokers. These 5 questions related to smoking were also cross-checked with each other. When 2 or more responses were contradictory, the whole record was examined and precedence given to the question involving the most detail concerning smoking. For example, if a student responded by marking the never smoking box and then gave details about age of starting smoking and gave further details about current smoking, that student was classified as a current smoker. Such editing was infrequent and involved less than 100 cases. The analyses were done separately for each sex. Age when smokers started smoking and the number of cigarettes they smoked per day were also analyzed for both current and former smokers.

The analysis was carried out in Stata using cross-tabulation and logistic regression. As the age range for this study is very wide (15-60 years), all results on smoking status by each sociodemographic-economic factor were age adjusted.

The research was approved by the Human Research Ethics Committee (Protocol: 2005/0350) of the Australian National University in late 2005.

\section{Results}

\section{Attributes of Respondents}

The main characteristics of the sample are shown in Table 1. Gender differences were assessed across sociodemographic variables. Of the 84315 students included in the analysis, $45.4 \%(n=38235)$ were male and $54.6 \%(n=46080)$ were female. A small majority of respondents $(53.9 \%)$ in the sample was in the younger age group (15-29 years), an age class dominated by women $(61.1 \%)$, with most of the remainder aged between 30 and 44 years $(39.7 \%)$. These 3 age groups were selected by using a 15-year cutoff for young, middle-aged, and older age groups. Overall, the most common educational attainment was a high school education $(48.4 \%)$; women were about a fifth more likely than men to have university education $(26.6 \%$ vs $22.8 \% ; P<.001)$. Geographically, $24.5 \%$ and $17.2 \%$ were from the central region and Bangkok, respectively, with only $6.5 \%$ from the east. The representation from Bangkok, the north, and the east was very similar to the national population distribution. ${ }^{8}$

The respondents did not on average have a high income. Slightly more than half $(54.1 \%)$ earned 3001 to 10000 baht per month or approximately 94 to 313 US dollars. $^{\dagger}$ About half (52.7\%) were single, with rather more women than men having this status. The respondents were asked whether they had moved home since they were 12 years of age: $31.7 \%$ had moved from rural to urban areas and $4.3 \%$ from urban to rural areas; the rest remained where they had been living either in rural or urban areas (43.9\% rural at both times and $20.1 \%$ urban at both times).

Compared with the national adult population, the STOU students are younger with a higher level of education. There are more single persons among the students than in the national population, which could be related to the younger age of the students.

†The exchange rate is 33.66 Thai baht for 1 US dollar as of August 4, 2008, according to the Bank of Thailand. 
Table 1. General Characteristics of the Sample $(\mathrm{N}=84315)$

\begin{tabular}{|c|c|c|c|c|c|c|}
\hline \multirow{2}{*}{$\begin{array}{l}\text { Sociodemographic } \\
\text { Characteristics }\end{array}$} & \multicolumn{2}{|c|}{ Total } & \multicolumn{2}{|c|}{ Male } & \multicolumn{2}{|c|}{ Female } \\
\hline & $\mathrm{n}$ & Percentage & $\mathrm{n}$ & Percentage & $\mathrm{n}$ & Percentage \\
\hline \multicolumn{7}{|c|}{ Sample at their current ages } \\
\hline 15-29 Years & 45427 & 53.9 & 17275 & 45.2 & 28152 & 61.1 \\
\hline 30-44 Years & 33475 & 39.7 & 17376 & 45.5 & 16099 & 34.9 \\
\hline 45-60 Years & 5413 & 6.4 & 3584 & 9.4 & 1829 & 4.0 \\
\hline Total & 84315 & 100 & 38235 & 100 & 46080 & 100 \\
\hline \multicolumn{7}{|l|}{ Education } \\
\hline High school & 40704 & 48.4 & 20955 & 54.9 & 19749 & 43.0 \\
\hline Diploma/Certificate & 22817 & 27.1 & 8675 & 22.2 & 14142 & 30.8 \\
\hline University & 20574 & 24.5 & 8515 & 22.3 & 12059 & 26.2 \\
\hline Total & 84095 & 100 & 38145 & 100 & 45950 & 100 \\
\hline \multicolumn{7}{|l|}{ Region } \\
\hline Bangkok & 14353 & 17.2 & 5547 & 14.6 & 8806 & 19.2 \\
\hline Central & 20480 & 24.5 & 8581 & 22.7 & 11899 & 26.0 \\
\hline North & 15335 & 18.3 & 9211 & 19.7 & 8189 & 17.2 \\
\hline Northeast & 17400 & 20.8 & 7458 & 24.4 & 7877 & 17.9 \\
\hline East & 5143 & 6.5 & 4780 & 6.1 & 6161 & 6.2 \\
\hline South & 10941 & 13.1 & 2314 & 12.6 & 2829 & 13.5 \\
\hline Total & 83652 & 100 & 37891 & 100 & 45761 & 100 \\
\hline \multicolumn{7}{|c|}{ Personal monthly income } \\
\hline$<3000$ Baht & 9040 & 11.0 & 4318 & 11.6 & 9040 & 10.5 \\
\hline 3001-7000 Baht & 25286 & 30.7 & 8814 & 23.6 & 25286 & 36.7 \\
\hline 7001-10000 Baht & 19225 & 23.4 & 8582 & 23.0 & 19225 & 23.7 \\
\hline $10001-20000$ Baht & 20002 & 24.3 & 10607 & 28.4 & 20002 & 20.9 \\
\hline 20 001-30000 Baht & 5164 & 6.3 & 2872 & 7.7 & 5164 & 5.1 \\
\hline$>30000$ Baht & 3531 & 4.3 & 2118 & 5.7 & 3531 & 3.1 \\
\hline Total & 82248 & 100 & 37311 & 100 & 82248 & 100 \\
\hline \multicolumn{7}{|l|}{ Marital status } \\
\hline Single & 43867 & 52.7 & 17208 & 45.7 & 26659 & 58.5 \\
\hline Married & 32199 & 38.7 & 17503 & 46.5 & 14696 & 32.2 \\
\hline Others $^{\mathrm{a}}$ & 7217 & 8.7 & 1604 & 7.9 & 2007 & 9.3 \\
\hline Total & 83283 & 100 & 1359 & 100 & 2247 & 100 \\
\hline \multicolumn{7}{|c|}{$\begin{array}{l}\text { Home location when aged } \\
12 \text { years and now }\end{array}$} \\
\hline Rural-Rural & 36551 & 43.8 & 17071 & 45.3 & 19480 & 42.7 \\
\hline Rural-Urban & 26386 & 31.7 & 12181 & 32.3 & 14205 & 31.2 \\
\hline Urban-Urban & 3605 & 20.1 & 1651 & 18.0 & 1954 & 21.8 \\
\hline Urban-Rural & 16761 & 4.3 & 6805 & 4.4 & 9956 & 4.3 \\
\hline Total & 83303 & 100 & 37708 & 100 & 45595 & 100 \\
\hline
\end{tabular}

${ }^{\mathrm{a}}$ Other marital status covered separated, divorced, and widow.

\section{Smoking by Socioeconomic Factors}

Overall, $10.4 \%$ of the sample reported being current smokers, whereas $17.3 \%$ were former smokers, and $72.3 \%$ reported never having smoked. Smoking status differed substantially by sex. Only $1.0 \%$ of women were current smokers, in contrast with men, among whom $21.6 \%$ reported smoking currently. Similarly, only $4.7 \%$ of women but $32.5 \%$ of men were former smokers. Thus, the detailed analyses of influences on smoking patterns are restricted to men only.

Table 2 shows age-adjusted prevalence of smoking status in men for each sociodemographic factor. The prevalence of current smoking among men was similar at all ages, with about one fifth reporting the behavior. There was, however, a marked inverse trend in 
Table 2. Smoking Status in Men by Each Sociodemographic Factor $(\mathrm{n}=38235)^{\mathrm{a}}$

\begin{tabular}{|c|c|c|c|c|c|c|c|}
\hline \multirow{3}{*}{$\begin{array}{l}\text { Socioeconomic } \\
\text { Status }\end{array}$} & \multirow[b]{3}{*}{ Total $\mathrm{n}$} & \multicolumn{6}{|c|}{ Smoking Status } \\
\hline & & \multicolumn{2}{|c|}{ Current Smoker } & \multicolumn{2}{|c|}{ Former Smoker } & \multicolumn{2}{|c|}{ Never Smoker } \\
\hline & & $\mathrm{n}$ & Percentage & $\mathrm{n}$ & Percentage & $\mathrm{n}$ & Percentage \\
\hline \multicolumn{8}{|c|}{ Current age of the sample } \\
\hline 15-29 Years & 17275 & 3513 & 20.0 & 4245 & 24.6 & 9517 & 55.4 \\
\hline 30-44 Years & 17376 & 4029 & 23.0 & 6420 & 37.0 & 6927 & 39.9 \\
\hline 45-60 Years & 3584 & 708 & 19.8 & 1757 & 49.2 & 1119 & 30.9 \\
\hline \multicolumn{8}{|l|}{ Education level } \\
\hline High school & 20955 & 5187 & 30.1 & 7019 & 34.7 & 8749 & 35.1 \\
\hline Diploma/certificate & 8675 & 1857 & 21.4 & 2787 & 32.7 & 4031 & 46.0 \\
\hline University degree & 8515 & 1185 & 13.2 & 2584 & 27.6 & 4746 & 59.1 \\
\hline \multicolumn{8}{|l|}{ Personal income } \\
\hline$<3000$ Baht & 4318 & 1005 & 28.4 & 1058 & 30.0 & 2255 & 41.6 \\
\hline 3001-7000 Baht & 8814 & 2029 & 24.4 & 2440 & 31.3 & 4345 & 44.3 \\
\hline 7001-10 000 Baht & 8582 & 1845 & 21.0 & 2726 & 33.1 & 4011 & 45.9 \\
\hline 10 001-20 000 Baht & 10607 & 2223 & 19.3 & 3927 & 33.1 & 4457 & 47.6 \\
\hline 20 001-30 000 Baht & 2872 & 534 & 18.0 & 1146 & 28.3 & 1192 & 53.3 \\
\hline$>30000$ Baht & 2118 & 341 & 18.0 & 859 & 28.1 & 918 & 53.4 \\
\hline \multicolumn{8}{|l|}{ Marital status } \\
\hline Single & 17208 & 3511 & 20.5 & 4137 & 25.6 & 9560 & 53.9 \\
\hline Married & 17503 & 3715 & 24.0 & 7011 & 41.0 & 6777 & 34.8 \\
\hline Other marital status ${ }^{\mathrm{b}}$ & 2963 & 853 & 28.4 & 1057 & 38.3 & 1053 & 33.3 \\
\hline \multicolumn{8}{|l|}{ Geographic region } \\
\hline Bangkok & 5547 & 1152 & 20.6 & 1756 & 31.0 & 2639 & 48.4 \\
\hline Central & 8581 & 1771 & 20.3 & 2700 & 31.5 & 4110 & 48.3 \\
\hline North & 7458 & 2105 & 18.6 & 3116 & 33.8 & 3990 & 47.7 \\
\hline Northeast & 9211 & 1404 & 22.6 & 2523 & 33.8 & 3531 & 43.7 \\
\hline East & 2314 & 1269 & 19.6 & 1432 & 33.1 & 2079 & 47.1 \\
\hline South & 4780 & 456 & 26.5 & 765 & 30.7 & 1093 & 43.0 \\
\hline \multicolumn{8}{|c|}{$\begin{array}{l}\text { Home location when } \\
\text { aged } 12 \text { years and now }\end{array}$} \\
\hline Rural-Rural & 17071 & 3514 & 20.5 & 5423 & 32.5 & 8134 & 46.9 \\
\hline Rural-Urban & 12181 & 2483 & 19.8 & 4245 & 34.1 & 5453 & 46.0 \\
\hline Urban-Rural & 1651 & 469 & 28.2 & 544 & 31.1 & 638 & 40.7 \\
\hline Urban-Urban & 6805 & 1661 & 24.2 & 2027 & 29.2 & 3117 & 46.5 \\
\hline
\end{tabular}

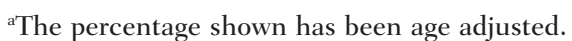

${ }^{\mathrm{b}}$ Other marital status covered divorced, widowed, separated, and living with partners.

prevalence of current smoking with education $(P<.001)$ as shown in Table 3 , with respondents with a university degree having the lowest proportion of current smokers $(13.2 \%)$, more than 2 times less than for those with high school education (30.1\%). The respondents with a high school education also had more former smokers $(34.7 \%)$ than other education groups. Likewise, the prevalence also decreased steadily with higher levels of income: $28.4 \%$ of those with an income of less than 3000 baht reported currently smoking compared with $18.0 \%$ among those with incomes above 30000 baht. A trend test showed statistical significance $(P<.001)$ for both education and income. However, some of the income effects disappeared after adjusting for education (Table 3). Smoking was also somewhat more prevalent in the small group who reported other marital statuses $(28.4 \%)$ than it was for those who were married $(24.0 \%)$ or single $(20.5 \%)$. Apart from an elevation among respondents who resided in the south $(26.5 \%$ current smokers), there was little difference across geographic regions. Those who were urbanized at young ages reported higher 
Table 3. Relationship Between Male Current Smokers and Education and Income Levels (Age Adjusted)

\begin{tabular}{|c|c|c|c|c|}
\hline \multirow[b]{2}{*}{ Factor $^{\mathrm{a}}$} & \multicolumn{2}{|c|}{ Odds Ratio } & \multirow[b]{2}{*}{ 95\% Confidence Interval } & \multirow[b]{2}{*}{$P($ trend $)$} \\
\hline & Crude & Adjusted & & \\
\hline Education level & & & & .000 \\
\hline High school & 1.00 & 1.00 & - & \\
\hline Diploma/certificate & 0.84 & 0.84 & $0.8-0.9$ & \\
\hline University degree & 0.50 & 0.51 & $0.5-0.5$ & \\
\hline Personal income & & & & .014 \\
\hline$<3000$ Baht & 1.00 & 1.00 & - & \\
\hline 3001-7000 Baht & 0.98 & 1.00 & $0.9-1.1$ & \\
\hline 7001-10 000 Baht & 0.90 & 0.98 & $0.9-1.1$ & \\
\hline $10001-20000$ Baht & 0.88 & 0.99 & $0.9-1.1$ & \\
\hline $20001-30000$ Baht & 0.75 & 0.93 & $0.8-1.1$ & \\
\hline$>30000$ Baht & 0.63 & 0.80 & $0.7-0.9$ & \\
\hline
\end{tabular}

${ }^{\mathrm{a}}$ For education level, secondary education was used as the reference, and for income level, $<3000$ baht was used as the reference.

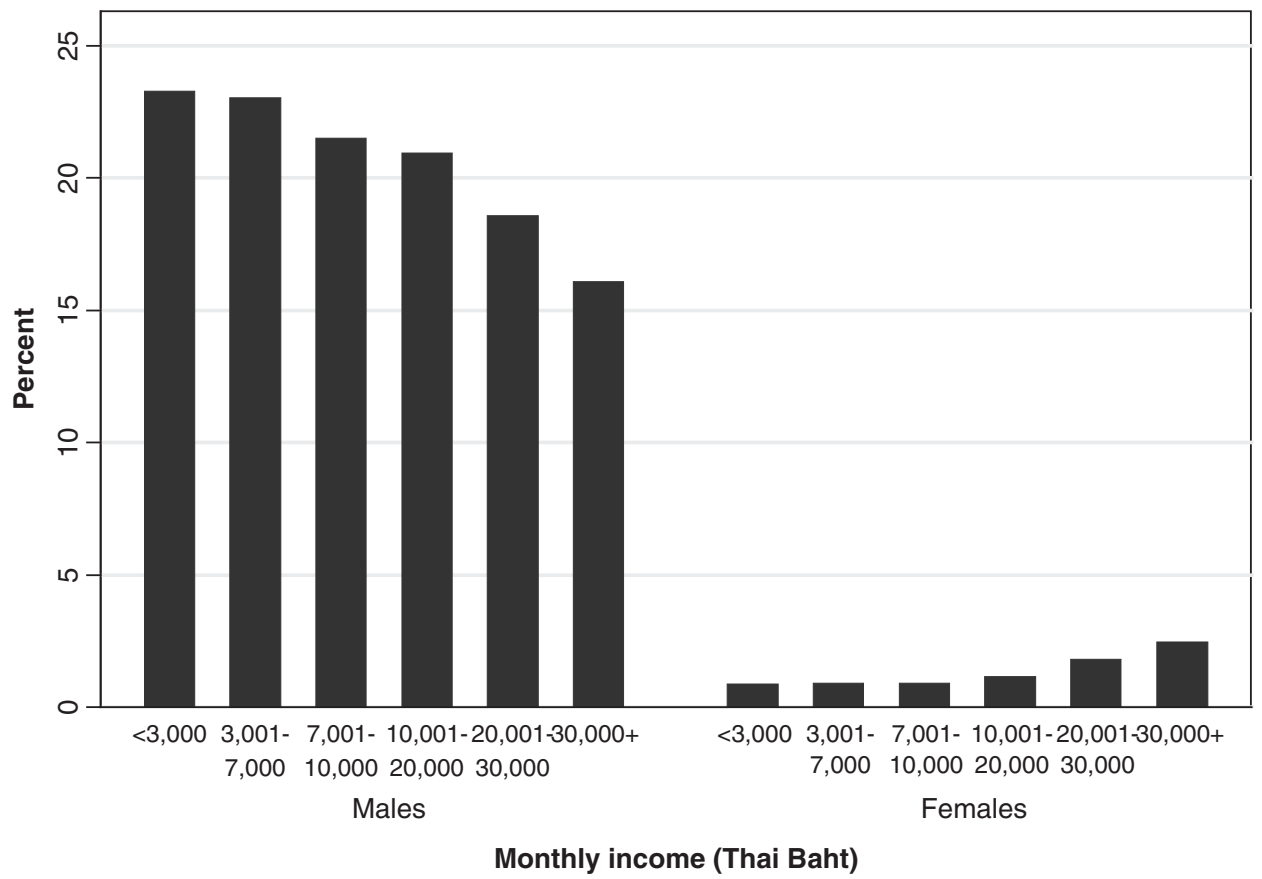

Figure 1. Percentage of current smokers by level of personal monthly income.

levels of current smoking $(28.2 \%$ and $24.2 \%)$ than those from rural settings $(20.5 \%$ and $19.8 \%)$.

Among the small numbers of women smoking currently, the relation with income appeared to be opposite to that in males (increasing from $0.9 \%$ to $2.5 \%$ as income increased from lowest to highest; Figure 1), whereas as far as education was concerned, the proportion of current female smokers was similar across education levels $(0.1 \%)$. 
Table 4. Age When Male Former and Current Smokers Started Smoking, by Birth Cohort

\begin{tabular}{|c|c|c|c|c|c|c|}
\hline \multirow[b]{2}{*}{ Birth cohort } & \multirow[b]{2}{*}{$\mathrm{n}$} & \multicolumn{5}{|c|}{ Age When Smoking Commenced } \\
\hline & & $\begin{array}{l}\leq 12 \text { Years } \\
\quad(\text { PS })\end{array}$ & $\begin{array}{c}\text { 13-15 Years } \\
\text { (JHS) }\end{array}$ & $\begin{array}{l}\text { 16-18 Years } \\
\text { (SHS) }\end{array}$ & $\begin{array}{c}\text { 19-24 Years } \\
\text { (Uni) }\end{array}$ & $25+$ Years \\
\hline 1987-1990 (Age 15-18 years) & 49 & 12.2 & 46.9 & 40.8 & - & - \\
\hline 1981-1986 (Age 19-24 years) & 2746 & 6.8 & 31.7 & 37.7 & 23.7 & - \\
\hline $1971-1980$ (Age 25-34 years) & 9026 & 4.0 & 29.1 & 39.4 & 24.3 & 3.1 \\
\hline 1961-1970 (Age 35-44 years) & 5870 & 3.8 & 19.8 & 37.2 & 32.5 & 6.8 \\
\hline 1945-1960 (Age 45-60 years) & 2407 & 4.4 & 19.9 & 37.0 & 31.0 & 7.7 \\
\hline Total & 20098 & 4.4 & 25.7 & 38.2 & 27.4 & 4.3 \\
\hline
\end{tabular}

Abbreviations: PS, primary school age (year 1-6); JHS, junior high school age (year 7-9); SHS, senior high school ages (year 10-12); Uni, university age.

\section{Age When the Sample Started Smoking}

We found in the analysis that the highest proportions of the sample that had smoked had started smoking at the age of 18 years $(16.7 \%)$ and 15 years $(15.6 \%)$. Both men and women display similar patterns as regards the age at which they started smoking, which is highly concentrated at 15 to 20 years. When dividing the ages at which smoking started into 5 groups (ie, $<12$ years [primary school age], 13-15 years [junior high school age], 16-18 years [senior high school age], 19-24 years [university age], and 25 years or over [adult age]), it was found that more than $38.2 \%$ of smokers started smoking when they were in senior high school, whereas $27.5 \%$ and $25.6 \%$ started when they were in university and junior high school, respectively (Table 4). It should also be noted that more recent birth cohorts tended to initiate smoking at an earlier age than the older cohorts.

In Table 5, we see that the age at which respondents started smoking shows a negative relation with parents' education, in that the higher the education level of the parents, the higher the rate of starting smoking during the school ages. Hence, the rate of starting smoking at university and adult age decreased with higher levels of parental education.

Students who had been living in urban homes or who had moved from urban homes were more likely to have started smoking during the school years than those who had been living in rural homes or had moved from rural homes. Respondents who reside in Bangkok and the north and central regions started smoking at younger ages than those who resided in other regions of the country.

\section{Number of Cigarettes Smoked Per Day}

More than $25.0 \%$ of male current smokers reported smoking 10 cigarettes per day, and another $13.0 \%$ and $12.9 \%$ reported smoking 5 and 20 cigarettes per day, respectively. There is a clear trend toward an increasing number of cigarettes with age among male current smokers, as shown in Figure 2.

Women smoked fewer cigarettes than men. About half (51.0\%) of female current smokers reported smoking 1 to 4 cigarettes per day, and less than $9.0 \%$ reported smoking more than 10 cigarettes per day. Female current smokers also smoked less than male current smokers in most age groups with the exception of the 45-to-49 age group, where the mean of number of cigarettes smoked by women was higher than that for men, but the number of female smokers in this age group was very small $(n=10)$ and much less than the number of male smokers. 
Table 5. Association Between Parents' Education, Home Location, and Geographic Region and Starting Smoking at School Age (ie, 18 Years Old or Younger)

\begin{tabular}{|c|c|c|c|c|c|c|}
\hline \multirow[b]{2}{*}{$\begin{array}{l}\text { Socioeconomic } \\
\text { Factor }\end{array}$} & \multicolumn{6}{|c|}{ Started Smoking at School Age ( $\leq 18$ years) } \\
\hline & Percentage & $\begin{array}{l}\text { Crude } \\
\text { OR }\end{array}$ & $\begin{array}{l}\text { Adjusted } \\
\mathrm{OR}^{\mathrm{a}}\end{array}$ & $\begin{array}{l}\text { Adjusted } \\
\mathrm{OR}^{\mathrm{b}}\end{array}$ & $\begin{array}{l}\text { 95\% Confidence } \\
\text { Interval }\end{array}$ & $P$, Trend \\
\hline Mother's education & & & & & & .001 \\
\hline No formal education & 67.9 & 1.0 & 1.0 & 1.0 & - & \\
\hline Primary & 67.5 & 1.1 & 1.1 & 1.2 & $1.1-1.3$ & \\
\hline Secondary & 72.3 & 1.4 & 1.4 & 1.0 & $0.9-1.1$ & \\
\hline Tertiary & 76.7 & 1.5 & 1.6 & 1.1 & $1.0-1.2$ & \\
\hline Father's education & & & & & & .000 \\
\hline No formal education & 69.2 & 1.0 & 1.0 & 1.0 & - & \\
\hline Primary & 66.5 & 1.0 & 1.0 & 0.9 & $0.9-1.0$ & \\
\hline Secondary & 70.8 & 1.3 & 1.3 & 1.1 & $1.0-1.3$ & \\
\hline Tertiary & 75.3 & 1.3 & 1.4 & 1.1 & $1.0-1.3$ & \\
\hline $\begin{array}{l}\text { Home location when } \\
12 \text { years old and now }\end{array}$ & & & & & & .000 \\
\hline Rural-Rural & 67.0 & 1.0 & 1.0 & 1.0 & - & \\
\hline Rural-Urban & 66.9 & 1.0 & 1.0 & 1.0 & $0.9-1.1$ & \\
\hline Urban-Rural & 74.6 & 1.5 & 1.5 & 1.5 & $1.3-1.6$ & \\
\hline Urban-Urban & 72.5 & 1.2 & 1.3 & 1.2 & $1.1-1.3$ & \\
\hline Geographic region & & & & & & .000 \\
\hline Bangkok & 70.7 & 1.0 & 1.0 & 1.0 & - & \\
\hline Central & 69.1 & 1.0 & 1.0 & 1.0 & $0.9-1.3$ & \\
\hline North & 70.2 & 1.1 & 1.1 & 1.2 & $1.1-1.3$ & \\
\hline Northeast & 65.9 & 0.9 & 0.9 & 0.9 & $0.9-1.0$ & \\
\hline East & 66.5 & 1.4 & 1.4 & 1.5 & $1.3-1.6$ & \\
\hline South & 67.4 & 0.9 & 1.0 & 1.0 & $0.9-1.1$ & \\
\hline
\end{tabular}

Abbreviation: OR, odds ratio.

${ }^{a}$ Odds ratios adjusted to age.

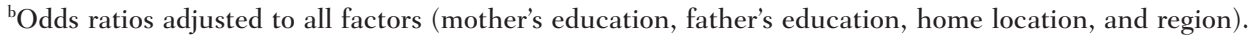

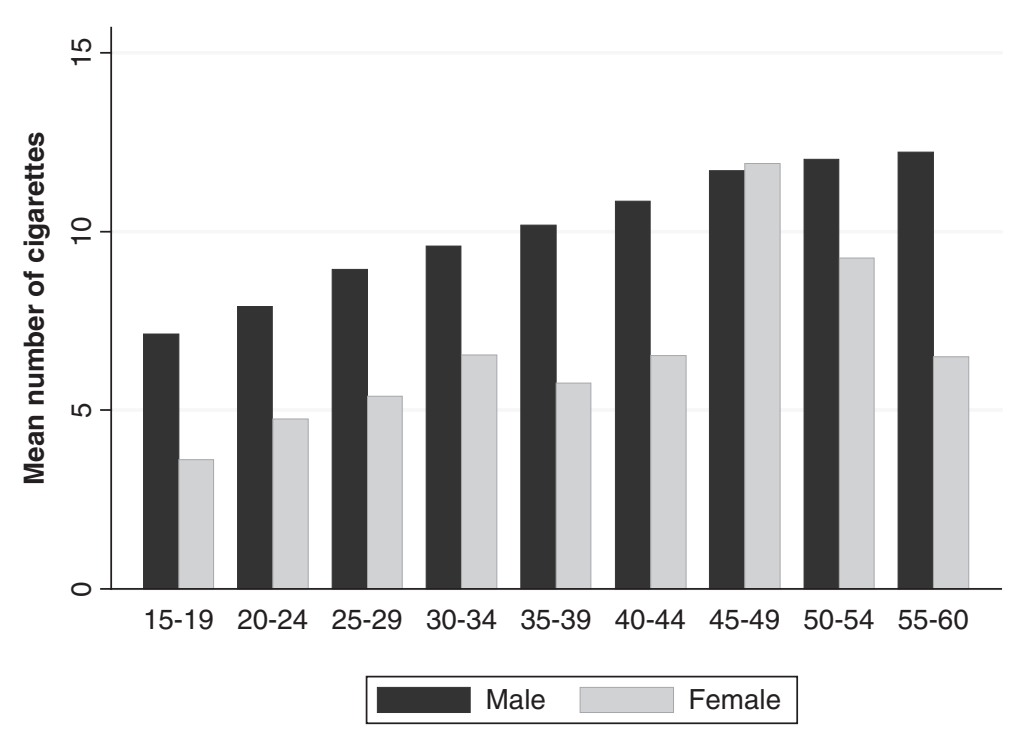

Figure 2. Average number of cigarettes smoked per day by male and female current smokers in each age group. 


\section{Discussion}

This study shows a striking difference in smoking prevalence for male and female students. Only $1.0 \%$ of women were current smokers, in contrast with men, among whom $21.5 \%$ reported smoking currently. Similarly, only $4.8 \%$ of women but $32.6 \%$ of men were former smokers. There was no constant age pattern of smoking in male current smokers as the highest proportion of current smokers was among those aged 30 to 44 years, whereas the younger (15-29 years) and older (45-60 years) groups had similar smoking proportions. However, the proportion of former male smokers increased with age: that is, more older respondents had quit smoking than younger ones. However, there is no further information available regarding this because the questionnaire only asked when they had quit but not the reason for quitting. Education and income could play a role in current smoking as the results show an inverse trend of current smoking with education and income.

Most of the sample started smoking at school age, especially at 16 to 18 years. More recent birth cohorts, on average, started smoking at an earlier age than the older birth cohorts. This could in part reflect the increasing proportion of young Thais who grow up in urban environments. Urban environments seem to be more conducive to smoking because we found that students who had been living in urban homes or who had moved from urban homes started smoking at school age compared with those who had been living in rural homes or had moved from rural homes. Surprisingly, the study found a negative relation between starting smoking at school age and parents' education, in that the higher the education level of the parents, the higher the rate of starting smoking at school age. Notably, more than $40 \%$ of families with parents having tertiary level of education lived in urban environments. It could be that the prosmoking effect of urban environments outweighed any antismoking effect of tertiary educated parents.

This study has some limitations in that it is a self-administered questionnaire survey, which received a response from $44 \%$ of the targeted sample. The other $56 \%$ who did not respond might have contributed to different results. However, we did note that the respondents were very similar to the overall student body for age, income, geographic area of residence, and occupation, all of which were described in the STOU's annual report for 2005. There are also limitations in the questionnaire itself. For instance, the questionnaire did not define types of cigarettes; it was assumed that all types of cigarettes either manufactured or self-rolled were included; this could have influenced the finding of a higher proportion of current smokers among the lower-income groups as self-rolled cigarettes are comparatively cheaper than the manufactured ones. In addition, the questionnaire asked at what age a former smoker stopped smoking. There were 7 students who responded that they had stopped at their current age and, therefore, may be they should not be considered as former smokers. However, such a small number of potentially misclassified cases should not produce any bias in the analysis.

Despite such limitations, this study has several strengths particularly because it covered a large sample from diverse geographic areas and varied social and educational backgrounds. These features make it very useful for the investigation of factors that influence smoking nationally. Also, because this sample is the younger adult population, they are literally the future of Thailand.

The proportion of current smokers in our sample is significantly lower than that in the general population, which a recent survey has shown to be $49.1 \%$ in men and $2.7 \%$ in women. ${ }^{9}$ Comparing across age groups, the smoking prevalence is also lower in each age group. These lower numbers can be attributable to the distinct characteristic of this sample who are openuniversity students with a higher level of education (at least high school) than the general 
population. As shown in the results, students with higher levels of education smoked less, further confirming the continuing importance among the young of educational achievement as a potential brake on smoking behavior, as seen in earlier surveys on smoking in the general population. ${ }^{10}$ Therefore, education could be a factor contributing to the difference in smoking between the STOU sample and the general population. Education could also help increase awareness of the harms of smoking.

Although smoking prevalence among women is low ( $1.0 \%$ reported as current smokers), there has been a recent 4-fold increase in smoking among Thai women aged 15 to 24 years, from $0.3 \%$ in 1999 to $1.3 \%$ in $2006 .{ }^{1}$ There is an obvious trend toward increase in smoking for women in the higher income groups of the STOU sample, which could be similar to the situation in the general female population. There should be campaigns against smoking targeting women to halt this trend toward a higher level of smoking among them, thereby preserving their historically low prevalence. Besides, smoking is higher among married men and those with other marital statuses, so female partners could play a role in influencing smoking cessation or preventing smoking in their male partners.

The findings also show that personal income has an influence on smoking and the number of cigarettes smoked per day. The subgroup with low incomes smoked a higher number of cigarettes though it was more likely that they smoked self-rolled cigarettes, which are considerably cheaper than the manufactured or imported cigarettes that are affordable only for those with higher incomes. ${ }^{11}$ The number of cigarettes smoked by the STOU student sample ( 9 cigarettes per day) is similar to the number smoked by the general Thai population (10 cigarettes per day on average). In addition, the number of cigarettes smoked by female STOU respondents is much lower than the number smoked by female students in other countries such as Australia. ${ }^{12}$ This could be because of cultural barriers, which make smoking an unacceptable behavior for women in Thailand.

Compared with neighboring countries, such as Malaysia, we found that the prevalence of smoking in women younger than 25 years is much lower than the prevalence among Malaysians of the same age. ${ }^{13}$ Moreover, smoking prevalence among Thai students is also lower than that in university students in other countries, both for male and female students. ${ }^{13-18}$ However, studies in many other countries were conducted specifically for on-campus university students, and the sample sizes were much smaller than those in our study, which covers a large number of students from an open university.

When we examined the ages at which our sample started smoking, we found that $95.6 \%$ started before the age of 25 , and a high proportion started at high school. This can be attributable to peer pressure and an external environment that provided temptations to start smoking. A survey of young adolescents (age 13-15 years) in Thailand found that $20 \%$ of respondents thought that boys who smoked were more attractive, and $58.3 \%$ responded that boys who smoked had more friends. ${ }^{19}$ This might be another reason why boys start smoking at school age. With a high proportion of high school students smoking, health education should focus on this part of the population.

Further analysis and study will be needed, particularly regarding the possible factors contributing to the difference in smoking prevalence between university students and the general population. The findings will provide good evidence for better policy making to reduce smoking prevalence in Thailand. Policies on smoking control in Thailand have been successfully implemented to reduce smoking prevalence by $25 \%$ from 1996 to 2006. Better specific target policies, for instance preventing the younger birth cohorts from starting smoking when they are in high school, will help reduce smoking prevalence in Thailand. Besides, research on the health and economic impacts of smoking among university students will alert smokers and make them more aware of the risks involved in smoking. 


\section{Conclusion and Recommendations}

The study found substantial differences between men and women in the proportion of smokers, with a higher percentage of men smoking in all sociodemographic categories compared with women. A higher proportion of the respondents in the younger age group also smoked.

It is recommended that for better and more effective smoking prevention and control, related policy measures should be formulated specifically for the younger age group in the Thai population and those adults with lower levels of education and income. Also, efforts should be made to preserve the low smoking rate among Thai women.

\section{Acknowledgments}

This study was supported by the International Collaborative Research Grants Scheme with joint grants from the Wellcome Trust UK (071587) and the Australian National Health and Medical Research Council (268055). We thank the Thai research team for providing the data, and we thank all the STOU students who participated in the study.

\section{References}

1. Wibulpolprasert S, ed. Thailand Health Profile 2005-2007. Nonthaburi, Thailand: Ministry of Public Health; 2008.

2. Wibulpolprasert S, ed. Thailand Health Profile 2001-2004. Nonthaburi, Thailand: Ministry of Public Health; 2005.

3. Burden of Disease and Injury in Thailand Project. Burden of Disease and Health Risks in Thai Population in 2004. Nonthaburi, Thailand: Ministry of Public Health; 2007.

4. Kasikorn Research Centre. Smoking Behaviours of Bangkok's Residents. Bangkok, Thailand: Kasikorn Research Centre; 2003.

5. Nanakorn S, Osaka R, Chusilp K, Tsuda A, Maskasame S, Ratanasiri A. Gender differences in health-related practices among university students in northeast Thailand. Asia Pac J Public Health. 1999;11:10-15.

6. Sleigh A, Seubsman S-a, Bain C; the Thai Cohort Study Team. Cohort profile: the Thai cohort of 87134 open university students. Int J Epidemiol. 2008;37:266-272.

7. National Statistical Office Thailand. Population and household survey 2000. http://service.nso. go.th/nso/nso_center/project/table/files/C-pop/2543/000/00_C-pop_2543_000_010000_01000. xls. Accessed March 20, 2009.

8. National Statistical Office Thailand. Key Statistics of Thailand 2005. Bangkok, Thailand: National Statistical Office, Ministry of Information and Communication Technology; 2005.

9. Porapakkham Y, Boonyarataphan P. Report of the National Health Examination Survey III 20032004. Nonthaburi, Thailand: Health Systems Research Institute; 2007.

10. Chokevivat V, Limwattananon S, Bundhamcharoen K, Prakongsai P, Tangcharoensathien V. Health risk distribution by socio-economic status and educational levels of Thai households: who smoked and drink more? J Health Sci. 2007;16(suppl);s1-s17.

11. Yong HH, Borland R, Hammond D, et al. Levels and correlates of awareness of tobacco promotional activities among adult smokers in Malaysia and Thailand: findings from the International Tobacco Control Southeast Asia (ITC-SEA) Survey. Tob Control. 2008;17:46-52.

12. Smith $\mathrm{D}$, Leggat $\mathrm{P}$. Tobacco smoking habits among a complete cross-section of Australian nursing students. Nurs Health Sci. 2007;9:82-89.

13. Manaf RA, Shamsuddin K. Smoking among young urban Malaysian women and its risk factors. Asia Pac J Public Health. 2008;20:204-213. 
14. Maziak W, Hammal F, Rastam S, et al. Characteristics of cigarette smoking and quitting among university students in Syria. Prev Med. 2004;39:330-336.

15. Steptoe A, Wardle J, Cui W, et al. An international comparison of tobacco smoking belief and risk awareness in university students from 23 countries. Addiction. 2002;97:1561-1571.

16. Haddad LG, Malak MZ. Smoking habits and attitudes towards smoking among university students in Jordan. Int J Nurs Stud. 2002;39:793-802.

17. Ohida T, Yokoyama E, Kaneita Y, Takemura S. Smoking among Japanese nursing students: nationwide survey. J Adv Nurs. 2005;49:268-275.

18. Saatci E, Inan S, Bozdemir N, Akpinar E, Ergun G. Predictors of smoking behaviour of first year university students: questionnaire survey. Croat Med J. 2004;45:76-79.

19. Rudatsikira E, Muula AS, Siziya S, Mataya RH. Correlates of cigarette smoking among schoolgoing adolescents in Thailand: findings from the Thai Global Youth Tobacco Survey 2005. Int Arch Med. 2008;1:8. 